\title{
La iglesia de San Pablo Apóstol de Zaragoza. Puesta en uso turístico y cultural de un monumento Patrimonio de la Humanidad
}

Sergio García Gómez ${ }^{a}$

${ }^{a}$ Iglesia parroquial de San Pablo de Zaragoza, C/San Pablo, 42, 50003 Zaragoza. sggzaragoza@gmail.com.

\begin{abstract}
Resumen
En el año 2001 la iglesia de San Pablo de Zaragoza fue declarada por la UNESCO Patrimonio de la Humanidad por ser uno de los mejores ejemplos del arte mudéjar aragonés. La parroquia de San Pablo se constituyó a mediados del siglo XIII y, desde entonces, su arquitectura y su patrimonio fueron ampliándose y enriqueciéndose a lo largo de los siglos. Su situación en el barrio de San Pablo, sumido en los años 80 y 90 del siglo XX en un grave proceso de degradación social y urbanística, hizo que el templo fuera casi olvidado por zaragozanos y visitantes.

En abril de 2015 la Parroquia puso en marcha un plan de gestión turística y cultural que podemos definir como inédito en el ámbito zaragozano. La iniciativa está destinada a facilitar la visita de la iglesia y torre mudéjar, y a promover el conocimiento de su rico patrimonio como espacio abierto a diferentes actividades culturales, sin olvidar el culto y las celebraciones religiosas del templo.
\end{abstract}

Palabras clave: arte mudéjar, arquitectura, Patrimonio Mundial, gestión del patrimonio, actividades turísticas.

\begin{abstract}
In 2001 the church of San Pablo de Zaragoza was declared a World Heritage Site by UNESCO for being one of the best examples of Aragonese Mudejar art. The parish was established in the middle of the 13th century and, since then, its architecture and heritage have been expanding and enriching throughout the centuries. Its situation in the San Pablo neighborhood, plunged in the 80s and 90s of the 20th century in a serious process of social and urban degradation, made the temple almost forgotten by the citizens and visitors.

In April 2015 the Parish launched a tourist and cultural management plan that we can define as unprecedented in the Zaragoza area. The initiative is intended to facilitate the visit of the Mudejar church and tower, and to promote the knowledge of its rich heritage as an open space for different cultural activities, without forgetting the temple's worship and religious celebrations.
\end{abstract}

Keywords: mudejar art, architecture, World Heritage, heritage management, tourist activities. 


\section{Introducción}

El 14 de Diciembre de año 2001 la iglesia de San Pablo de Zaragoza fue incluida por la Unesco en la Lista de Patrimonio Mundial por ser uno de los mejores ejemplos del arte mudéjar aragonés. La declaración de la "Arquitectura mudéjar de Aragón" supuso la ampliación de la declaración del Mudéjar de la ciudad de Teruel como Patrimonio Mundial realizada en el año 1986. Con este cambio, seis nuevos monumentos de Zaragoza y su provincia se sumaron a la Catedral, las torres de San Pedro, el Salvador y San Martín de la ciudad de Teruel. Entre los más de 150 edificios mudéjares conservados en Aragón la Unesco seleccionó para integrarse en el listado las iglesias de Tobed y Cervera de la Cañada, la Colegiata de Santa María de Calatayud, el palacio de la Aljafería, la Seo del Salvador y la iglesia de San Pablo de Zaragoza. De todos ellos se destacó especialmente su carácter singular, universal e irremplazable.

Esta declaración constituyó para la iglesia de San Pablo un hito en su reconocimiento patrimonial tras haber sido declarada anteriormente Monumento Nacional en 1931 y BIC por el Gobierno de Aragón en 2002.

La iglesia de San Pablo se sitúa en el corazón del Casco Histórico de Zaragoza, uno de los más extensos de España (Fig.1). La parroquia se constituyó a mediados del siglo XIII y, desde entonces, su arquitectura y su patrimonio fueron ampliándose y enriqueciéndose al igual que el barrio al que da nombre. Su opulencia llegó a tal punto que la iglesia era conocida en la ciudad como la "Tercera Catedral de Zaragoza". Pese a todos estos valores patrimoniales, históricos y culturales la iglesia es una gran desconocida para los ciudadanos y visitantes en la actualidad, por ello, desde el año 2015, se ha puesto en marcha un plan de gestión turística y cultural, único en la ciudad hoy día.

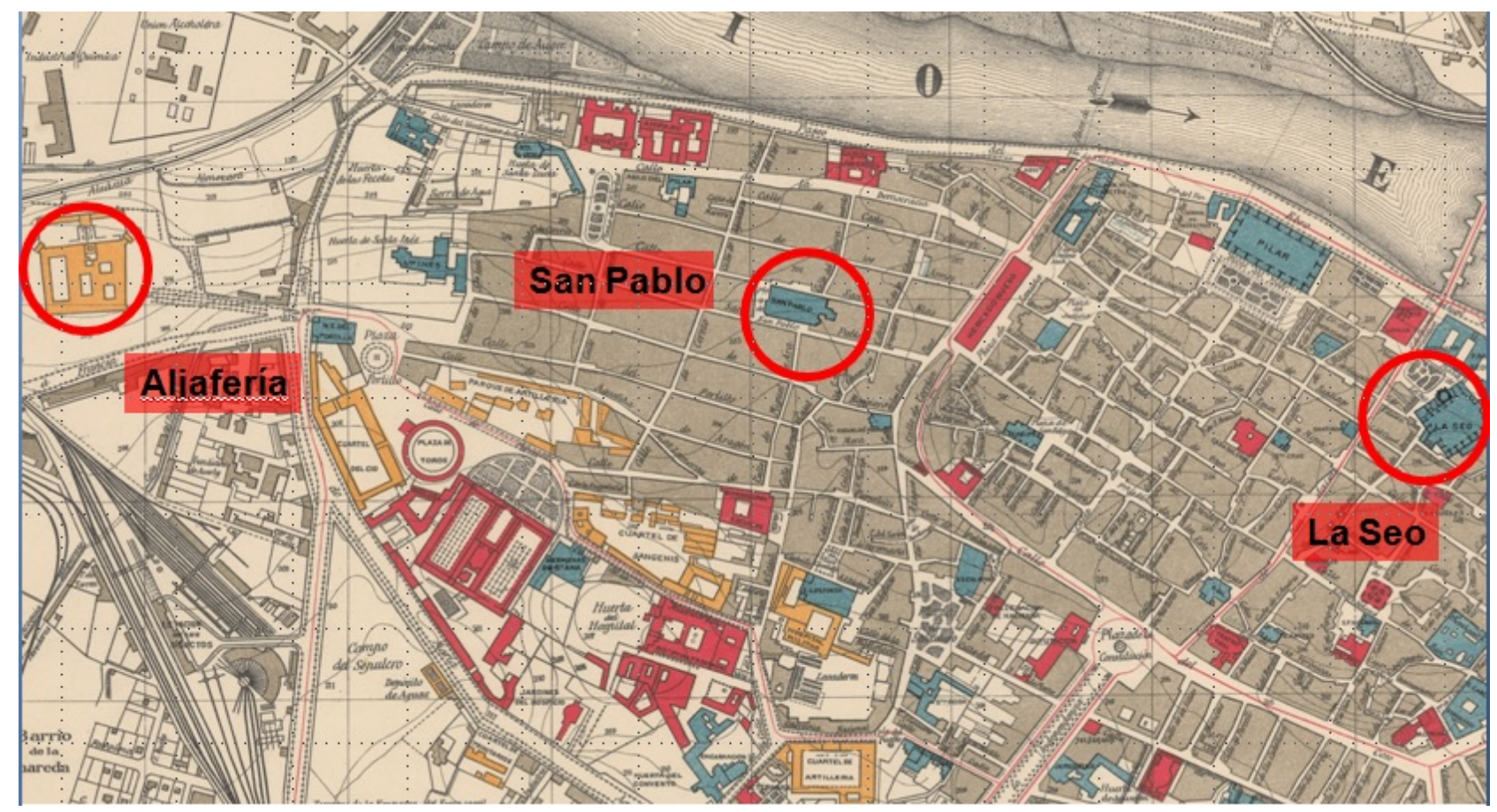

Fig. 1 Plano de situación de la iglesia de San Pablo. Dionisio Casañal. 1908. Archivo Municipal de Zaragoza

\section{Breve historia de la iglesia de San Pablo y situación}

Tras la conquista de la ciudad musulmana de Zaragoza en el año 1118 por el rey de Aragón Alfonso I el Batallador, en el espacio hoy ocupado por la iglesia de San Pablo, se creó una pequeña ermita dedicada a San Blas. Hasta entonces el lugar era utilizado principalmente como espacio agrícola y como cementerio. Poco a poco el entorno agrario se fue transformando en un nuevo barrio cuyo caserío fue paulatinamente rodeando la primitiva ermita. Debido al constante aumento de población en el año 1259 el Obispo Arnaldo de Peralta constituyó en el lugar de la antigua de ermita de San Blas, la nueva parroquia de San Pablo. 
La construcción de la actual iglesia se inició a partir del año 1289 a cargo de los mejores constructores y arquitectos de la ciudad, los maestros de obras mudéjares, es decir, por aquellos musulmanes que habían decidido quedarse en la ciudad tras la conquista cristiana. Los mudéjares conservaban su religión, leyes y tradiciones y también oficios como la arquitectura y la construcción. Resulta curioso que fueron los maestros de obras mudéjares los encargados de construir la nueva Zaragoza cristiana. Los mudéjares en la península desarrollaron un estilo artístico nuevo que fusionaba lo mejor del arte islámico con el arte cristiano que llegaba desde Europa, como el gótico que podemos ver en la iglesia de San Pablo, el hoy llamado Arte Mudéjar.

La primitiva iglesia de San Pablo estaba formada por un templo de una sola nave que corresponde hoy con la nave mayor, y una torre a sus pies, emblema hoy día del barrio de San Pablo con sus 66 metros de altura. En los siglos siguientes la iglesia se fue ampliando con la construcción de dos nuevas naves al norte y al sur, manteniendo el estilo mudéjar, el deambulatorio, la claustra y una serie de capillas que trajeron diferentes devociones y estilos artísticos al templo (Torralba, 1950).

En la actualidad podemos decir que se trata de un conjunto extraordinario, donde se unen diferentes estilos artísticos y elementos patrimoniales de gran relevancia. Entre ellos destaca su arquitectura mudéjar con la torre como gran emblema al tratarse de uno de los ejemplos más antiguos de este estilo en España (Fig. 2). Su antigüedad e influencia en la arquitectura mudéjar posterior fue unos de los motivos clave para su declaración como Patrimonio Mundial.

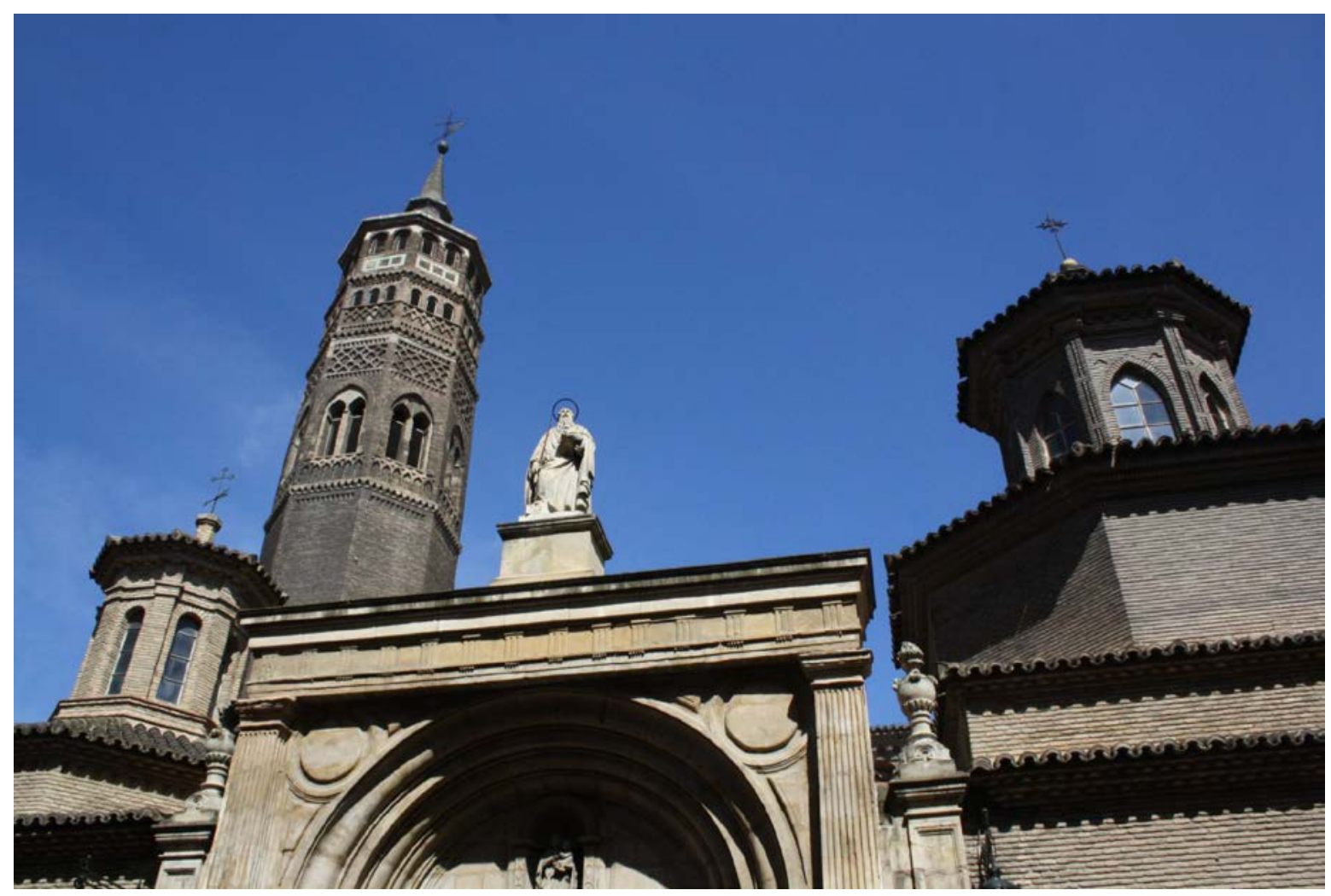

Fig. 2 Exterior de la iglesia y torre de San Pablo

En el interior de la iglesia destaca el retablo mayor con puertas (Fig. 3), único hoy día en la ciudad, creado por Damián Forment en el siglo XVI, el coro y órgano gótico del siglo XV e interesantes retablos y capillas de diferentes épocas.

Por otra parte, no podemos olvidar que la parroquia sigue estando muy viva y, a día de hoy, alberga numerosos cultos, tradiciones y celebraciones populares como las fiestas de San Blas o de San Antón, o la Semana Santa.

Sin embargo, a pesar de todos estos valores, reconocimientos e interés patrimonial, la iglesia de San Pablo es uno de los monumentos más desconocidos para los zaragozanos y visitantes. Su situación en el barrio de su mismo nombre, sumido, como tantos centros históricos de nuestro país, en los años 80 y 90 del siglo XX en un grave proceso de 
degradación social y urbanística, hizo que el templo fuera casi olvidado. Afortunadamente desde finales de los 90 se están desarrollando diferentes intervenciones de carácter social y urbanístico que están permitiendo, en mayor o menor medida, la reversión de estas problemáticas en la zona. La iglesia de San Pablo por su extraordinario valor patrimonial, tradición e historia debe obligatoriamente constituirse como un verdadero motor para favorecer la recuperación social, urbanística y económica del barrio.

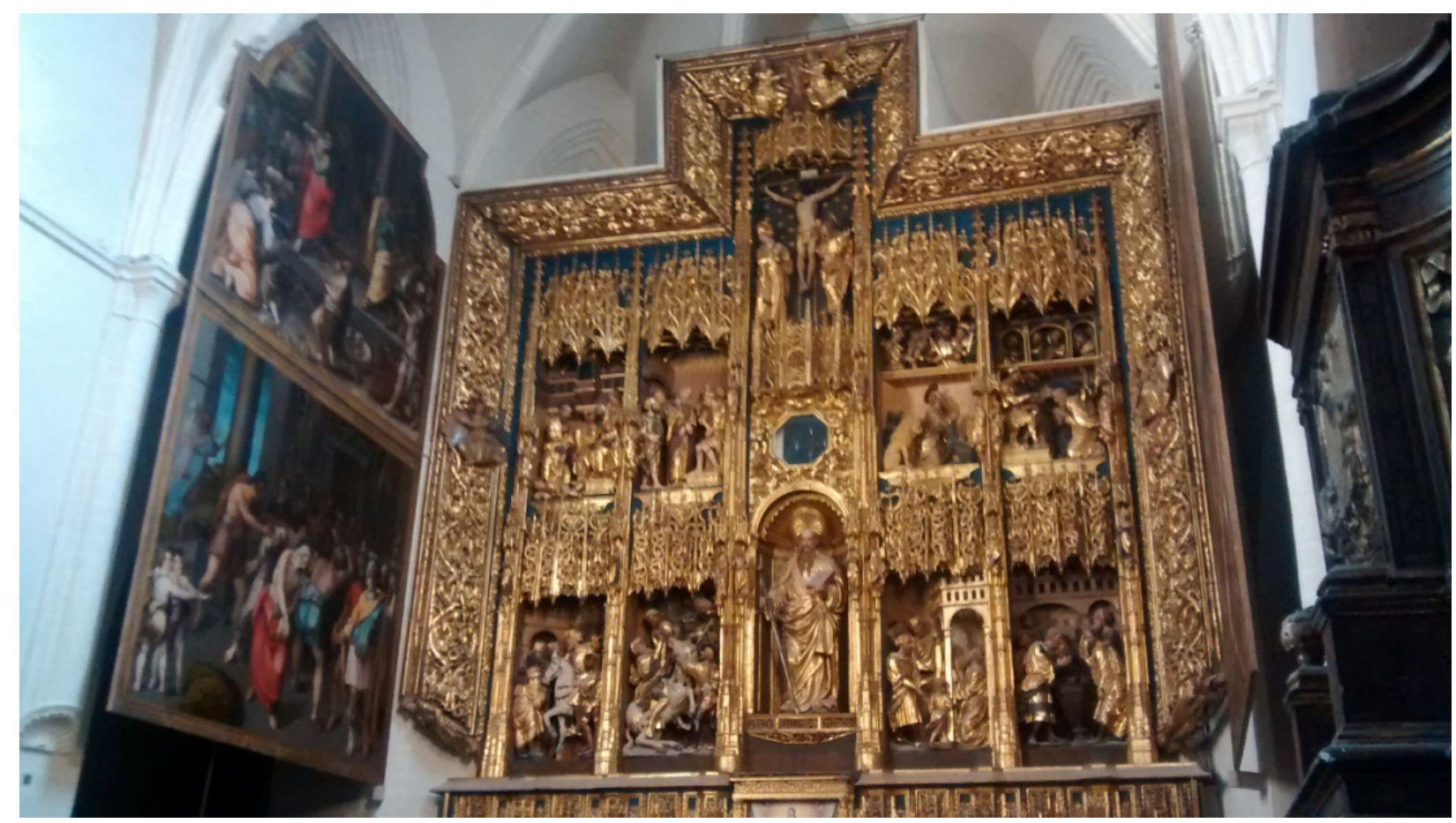

Fig. 3 Retablo Mayor de Damián Forment (s. XVI)

\section{Consecuencias de la declaración como Patrimonio Mundial}

La declaración de la iglesia de San Pablo como Patrimonio Mundial podemos decir que no ha servido, por el momento, como un verdadero impulso para promover una serie de actuaciones que aseguren su conservación, difusión y conocimiento. Tras una inicial euforia por parte de la clase política y el mundo cultural, con el paso de los años la declaración acabó, de alguna forma, diluyéndose y casi olvidándose en parte de Aragón.

En 2001, tras la declaración de la UNESCO, el Gobierno de Aragón, principal impulsor de esta declaración, plantearon el desarrollo de un ambicioso plan de puesta en valor de este extraordinario patrimonio. Por ejemplo, propusieron la creación de hasta 3 centros de interpretación sobre el mudéjar en la Comunidad, la celebración del día del Patrimonio Mundial en Aragón y aseguraron la realización de numerosas inversiones multimillonarias en restauración y difusión. De todo ello hoy, casi 20 años después, existe sólo una mínima parte realizada, principalmente restauraciones, y por ejemplo, no se ha creado ninguno de los centros de interpretación propuestos en su momento. Sí que hay que reconocer que se ha intervenido y restaurado en numerosos edificios mudéjares de la comunidad y que la iniciativa local ha desarrollado interesantes proyectos como los que encontramos en localidades como Tobed, donde se ha puesto en marcha un pequeño centro de interpretación y se ha abierto al uso turístico su monumental iglesia. En los últimos años se ha puesto en marcha la iniciativa Territorio Mudéjar, auspiciada por la Diputación Provincial de Zaragoza, y que busca aglutinar y promover el patrimonio mudéjar de los pequeños municipios como un recurso de desarrollo local.

Por último, respecto a la iglesia de San Pablo, a día de hoy sigue sin contar con un plan director que facilite las complejas labores de restauración y conservación necesarias en un monumento como este. La difusión turística y cultural en Zaragoza y Aragón, además, casi siempre se olvida de nombrar a San Pablo como Patrimonio Mundial y, en cambio, se utiliza una expresión genérica como es Mudéjar Patrimonio Mundial que contenta a más pueblos y ciudades con ejemplos del arte mudéjar, pero que no centra la atención en los verdaderamente reconocidos por la UNESCO. 


\section{Puesta en uso turístico y cultural de la iglesia de San Pablo}

Ante este panorama, en abril del año 2015 la Parroquia puso en marcha, por iniciativa propia y sin apoyo directo de ninguna entidad, tanto civil como eclesiástica, un plan de gestión turística y cultural que podemos definir como inédito en el ámbito zaragozano.

Tras las últimas labores de restauración de la iglesia que se habían llevadas a cabo en el retablo mayor en 2005 y la recuperación de las puertas del mismo en 2014 (Morte y Carrassón, 2007), se vio por parte de los responsables de la parroquia la necesidad de abrir este patrimonio a los visitantes y que no quedara cerrado e inaccesible tras la importante inversión económica realizada por parte del Ministerio de Cultura, a través del IPCE, y la propia Parroquia.

Para desarrollar el plan se contrató a un Gestor del Patrimonio (el autor de la comunicación) por parte de la Parroquia para gestionar los usos turísticos y culturales, y coordinar y desarrollar las visitas turísticas y actos que se realizan en el templo. La iniciativa está destinada principalmente a desarrollar un plan de gestión que permita facilitar la visita de la iglesia y la torre mudéjar, y a promover el conocimiento de su rico patrimonio como espacio abierto a diferentes actividades culturales, sin olvidar el culto y las celebraciones religiosas del templo. Por otra parte se realiza una vigilancia del estado del monumento diariamente y se plantean diferentes medidas de conservación y mantenimiento del patrimonio más desconocido.

El Plan de Gestión desarrollado se articula en tres ejes principalmente:

1. Las visitas turísticas y culturales

2. Los actos culturales y musicales.

3. Difusión y promoción

\subsection{Visitas turísticas y culturales}

Para desarrollar el plan de visitas, en primer lugar se procedió a estudiar la situación de la iglesia de San Pablo y conocer los sistemas de gestión de otros templos con características similares en toda España. Tras ello, una de las primeras medidas fue establecer un horario concreto y estable de apertura del monumento para los visitantes; con ello se buscaba facilitar la visita de la iglesia de San Pablo que hasta entonces únicamente permanecía abierta en horario de culto. A día de hoy, y exceptuando la Seo del Salvador y la Basílica del Pilar, es la única iglesia de Zaragoza que cuenta con horarios de visita turística por lo que continúa siendo muy complicado conocer el rico patrimonio eclesiástico de la ciudad.

Una segunda medida fue establecer unas tarifas de visita del monumento y que varían dependiendo del tipo de visita y visitante. La recaudación obtenida con las visitas se destina íntegramente al mantenimiento del templo y al desarrollo de la propia actividad turística.

Para conocer la iglesia de forma habitual se han creado dos tipos de visita diferenciados: la visita libre y la visita guiada "Mudéjar y más".

La visita libre permite, dentro del horario establecido y por un pequeño importe, visitar de forma individual los espacios más destacados de la iglesia. Con la entrada se encienden la iluminación del templo y se facilita una guía en español o inglés donde se destacan los elementos más importantes de los espacios incluidos en la visita.

Las visitas guiadas "Mudéjar y más" son realizadas por un guía oficial de Gobierno de Aragón, tal como marca la Ley de Turismo del Gobierno de Aragón. Se trata de una visita general que recorre los principales espacios de la iglesia y, además, incluye el acceso al interior de la torre y la subida a pie hasta el piso de campanas. La torre de San Pablo es la única torre mudéjar de la ciudad abierta a los visitantes de forma habitual y estable. 

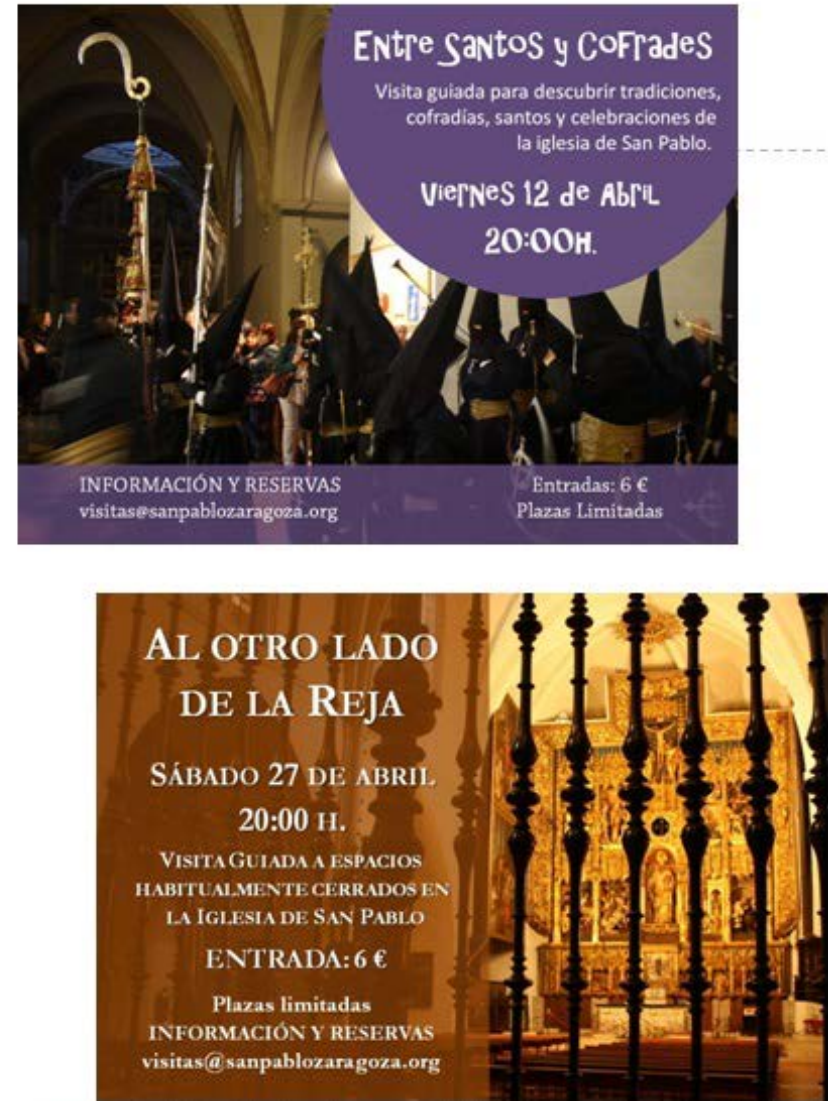

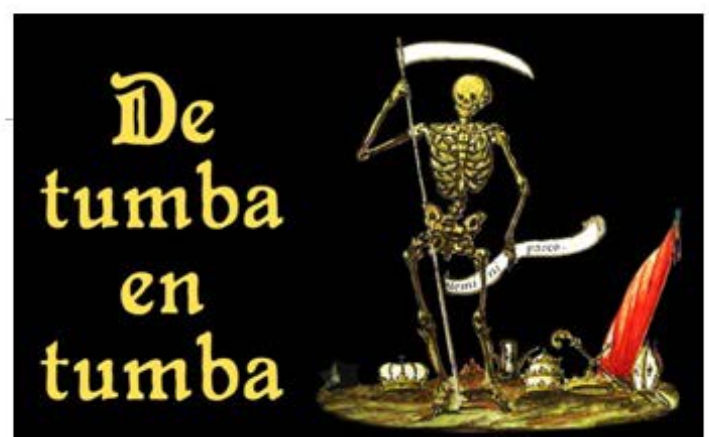

La muerte en la iglesia de San Pablo

VISITAS GUIADAS AÑo 2019

A las 19:30 h., previa reserva, los días

- $26,27,29,30$ y 31 de octubre

- 1,2 y 3 de noviembre

\section{Entrada: $7 €$}

Plazas limitadas

Información y reservas:

visitas@sanpablozaragoza.org

Fig. 4 Visitas especiales en la iglesia de San Pablo

Además, se han creado una serie de visitas especiales para grupos y visitas más específicas que exploran aspectos singulares de la parroquia. Las visitas especiales o "Premium" (Fig. 4) se realizan a lo largo de todo el año de forma puntual y son las siguientes:

- Educativa (ofrecida a escolares desde primaria a bachillerato)

- "De tumba en tumba" (Dedicada a la muerte y las tradiciones funerarias en la Parroquia)

- Al otro lado de la reja (Visita musical, dedicada a nuestro órgano gótico)

- Entre santos y cofrades (Recorrido por las devociones y tradiciones populares en la Parroquia)

- Noche de verano en la torre de San Pablo (Visita nocturna a la torre mudéjar)

- Ante las Puertas de San Pablo (Acto musical y cultural con el cierre de las puertas del retablo mayor)

- Navidad en San Pablo (Visita a la colección de Belenes del Mundo y al patrimonio navideño de la iglesia)

Así mismo, desde 2015, colaboramos en una serie de actividades culturales que se desarrollan en la ciudad como la Noche en Blanco o la Carrera del Gancho, ofreciendo visitas y actividades especiales adaptadas a las distintas programaciones

Otra de las iniciativas desarrolladas para dar a conocer nuestro patrimonio ha sido la apertura de una pequeña salamuseo donde se exponen una selección de bienes artísticos de la Parroquia y que no contaban con un espacio idóneo de exposición. Este espacio se ha concebido como un lugar vivo ya que en él se muestan algunas piezas de carácter permanente y, otras, de carácter temporal que se van renovando para vincular el contenido de la sala-museo a los tiempos litúrgicos, los meses del año o las visitas especiales. 


\subsection{Actos culturales y musicales}

En el plan de dinamización de la iglesia de San Pablo también hay que resaltar la apertura del templo a la realización de conciertos a lo largo del año. La buena acogida por parte del público de este tipo de actividades ha convertido a San Pablo en los últimos años en una referencia musical en la ciudad de Zaragoza. En el año 2019, por ejemplo, se han llegado a realizar 18 conciertos de diferentes tipos de música (Fig. 5).

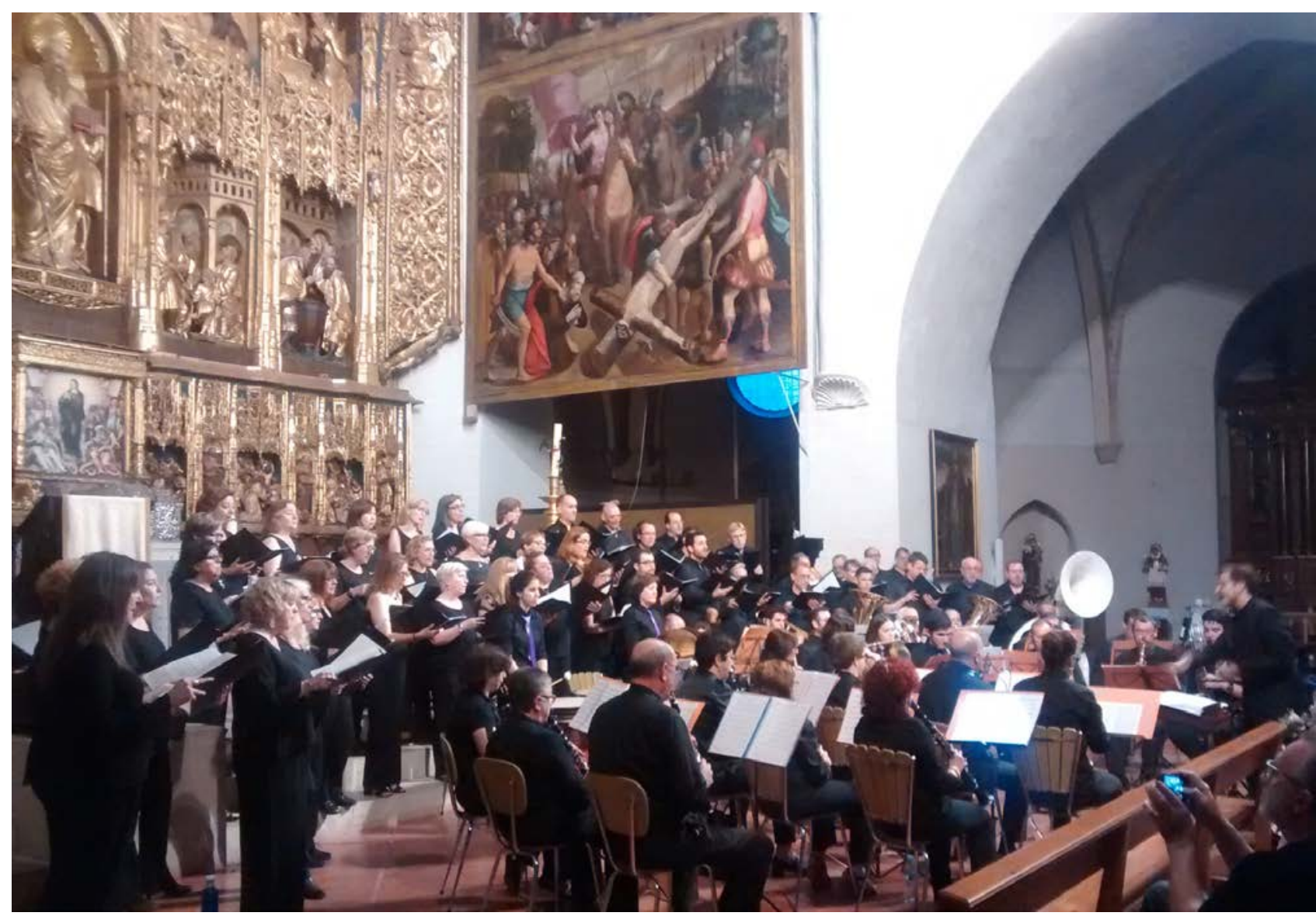

Fig. 5 Concierto en la nave mayor de la iglesia

\subsection{Difusión y promoción}

El desarrollo de todas estas actividades necesita una importante difusión pero la capacidad de la Parroquia para invertir en este aspecto es practicamente nula. Además, tampoco contamos con el apoyo de otras instituciones locales y regionales para realizar por ejemplo, material impreso de forma conjunta para la difusión del monumento o del Patrimonio Mudéjar.

Para suplir estas carencias ha sido necesario apoyarse en herramientas gratuitas que nos brindan las nuevas tecnologías y de ésta forma difundir las actividades que acoge la iglesia de San Pablo. En el año 2015 se puso en marcha el perfil propio de la iglesia de San Pablo en la red social Facebook y en el año 2017 en Instagram (@sanpablozaragoza). Su actualización y renovación es bastante activa y se ofrece información de la parroquia, curiosidades, historias, el santoral y otros elementos visuales vinculados e ilustrados con el variado patrimonio de la iglesia. En la actualidad se cuenta con más de 1400 seguidores en Facebook y más de 700 en Instagram.

Por otra parte, la iglesia de San Pablo cuenta con una activa y completa página web (www.sanpablozaragoza.org), donde se ofrece la agenda actualizada mes a mes y la información de actos religiosos, patrimoniales y culturales. 
También es necesario citar la importancia de los medios de comunicación locales como la Televisión Autonómica, las radios y la prensa; estos medios de gran alcance siempre son de gran ayuda para la difusión y, además, a coste cero para la Parroquia.

Por último, en los últimos meses se está trabajando en el desarrollo de una imagen común para la cartelería, folletos, tickets y cartelas informativas con el objetivo de mejorar la comunicación al ciudadano y visitante, haciéndola más atractiva y clara.

\section{Conclusiones}

Como conclusión podemos decir que el templo de San Pablo, poco a poco, está ocupando el lugar que le corresponde como referente patrimonial de la ciudad de Zaragoza, a pesar de la escasa colaboración institucional de las autoridades civiles y eclesiásticas. Sin embargo, sería deseable en los próximos años el desarrollo de un plan conjunto de difusión del arte mudéjar de Aragón que involucre a todas las instituciones y entidades. Igualmente sería deseable la puesta en marcha de un Plan Director para asegurar la correcta conservación y restauración del monumento.

En los casi cinco años que lleva en desarrollo este plan de gestión turística y cultural el número de visitantes no deja de crecer, lo que demuestra que el espacio tiene interés y la gente responde a la apertura del patrimonio. Además, en estos años la iglesia de San Pablo se ha convertido en un referente musical en Zaragoza; los numerosos conciertos con una gran afluencia de público se han convertido en un verdadero revulsivo para el barrio y la ciudad.

\section{Referencias}

Torralba, F. (1950). La insigne iglesia de San Pablo de Zaragoza. Zaragoza: IFC.

Morte, C., y Carrassón, A. (2007). El retablo mayor de la iglesia parroquial de San Pablo de Zaragoza. Restauración 2006. Zaragoza: Ministerio de Cultura, Gobierno de Aragón y Caja Inmaculada. 